\title{
Development of Management in the Digital Era
}

\author{
Raisya I. Akmaeva ${ }^{1, *}$ Aygul A. Aytpaeva ${ }^{2}$ Edvard I. Glinchevskiy ${ }^{3}$ \\ Bakhyt Zhautikov ${ }^{4}$
}

\author{
${ }^{1}$ Chair of Management, Astrakhan State University, Astrakhan 414056 Russia \\ ${ }^{2}$ Chair of Agricultural Technologies, Engineering, \& Agribusiness, Astrakhan State University, Astrakhan 414056 \\ Russia \\ ${ }^{3}$ Chair of English Language for Economics, Astrakhan State University, Astrakhan 414056 Russia \\ ${ }^{4}$ Rector, Karaganda State Industrial University, Karaganda 101400, Kazakhstan \\ *Corresponding author.Email: akmaevari@yandex.ru
}

\begin{abstract}
This paper concerns new tendencies and challenges of the $21^{\text {st }}$ century that present-day companies have to face under conditions of the digital economy. It presents the core principles of the new version of management "Management 2.0." and argues that digital transformation is the main driving force that can give Russia a new chance to eliminate its technological backwardness and help managers select efficient new business models and development strategies. Studies of the evolution of management concepts over the last decades make it possible to determine the main ideas of efficient management that may be adopted by a $21^{\text {st }}$ century manager. Present-day Russian managers have to make their companies competitive, which is possible only provided a company is changing at the same pace as the outside world and every employee is involved in the process of innovation on a regular basis. The article emphasizes the necessity to consider with the specifics of the Russian mentality that hampers the development of management in the digital economy. It proves that the necessary condition to introduce digital innovations successfully is new organizational forms of companies that encourage their staff to create a real value for their clients.
\end{abstract}

Keywords: principles of management, new version of management, digital tools, Agile software development,

holacracy, self-managing teams, change of business models, reduction of planning horizon, specifics of

Russian mentality

\section{INTRODUCTION}

It is a generally recognized fact that the principles of management developed over 100 years ago do not meet the economic reality of the $21^{\text {st }}$ century. The old version of management has become outdated as a paradigm of the industrial era based on the principles of standardization, specialization, hierarchy, control, and owners' interests as the top priority. In contrast, a $21^{\text {st }}$-century organization faces new challenges and tendencies, the main of which is an incredibly increased pace of technological modernization, especially owing to digitalization of economy.

Another specific feature is hypercompetition, which requires that companies should apply a new approach towards competition; they ought to become more creative and inventive, i.e. determine and sustain their core competencies and dynamic abilities on a regular basis by manufacturing what they can produce better than their competitors can.

The processes of digital transformation require reconsideration of business models and diversified activities; as a result, boundaries between industries are becoming vague. The main approach to business administration is reconsidered as well, i.e. a business model is changing by integrating cutting-edge technologies in new fields of business activities.

Not only business development models are changing, but also horizons of strategy development are reduced significantly, since they are reconsidered not once a year, but more frequently; new organizational forms of their planning and realization are demanded. Organizational structures are becoming flatter; self-managing teams are established; their members participate in management decision-making actively; their roles change; they become more responsible and trust each other more.

The present-day world of management requires both a new type of a manager - a leader who believes that the most important thing in his/her work is to motivate people and sustain their team spirit - and staff's active participation in reorganization and management decision-making [1].

Therefore, the new version of management should be based on such top-priority factors of efficient management as:

- orientation towards social aspects of a "self-learning" organization, which relates to a complete unleashing of staff's intellectual potential, encouragement of team selforganization and creativity; 
- flexibility of internal mechanisms of management systems and their compliance with the adopted strategy; - adaptability to constant changes in the external environment [2].

\section{BACKGROUND}

To make their companies perform in the $21^{\text {st }}$ century successfully, managers ought to recognize the fact that "Management 1.0" has become out-of-date and if a company continues to apply the old management methods, it will go under in the short-term run. Now management needs new daring and bold goals that would make managers search for entirely new ways to mobilize and realize the human potential. How could one restructure the whole management system under conditions of constant changes, so that a company not only achieved the set goals, but also adapted to new circumstances easily and sustained its competitiveness? How could a company develop and implement technological innovations and digital tools to keep the pace with the times? How could it rebuild the organizational forms of its staff's work to encourage its employees to take an initiative and do their best?

To find the right answers to these questions, researchers of the theory and practice of management gathered at an international conference arranged by the Management Lab in United States in May 2008. They developed the concept "Management 2.0: the New Version for a New Century" that included the 25 most significant tasks [3].

The first and foremost task is to set high goals that should relate to tackle socially-oriented and noble tasks, not to extract as much profit as one can, as most companies do now. The second task is to adopt the idea of corporate responsibility, which implies considering with interests of not only top management and stockholders, but also their staff and the society in general. The third task is to require development of a new understanding of the essence and philosophy of management, which implies that an organization of the future should adapt to any changes easily, develop its innovations permanently, and be socially responsible by extracting ideas from various fields of knowledge.

The fourth task is of revolutionary character; it implies rejection of the traditional hierarchy and its substitution with a "natural" one, when one's status and authority depends not on their official position, but on their contribution.

In 2008, these new tasks of management seemed to be quite revolutionary, especially for regional managers, as the 2012 and 2014 surveys conducted among trainees of the Presidential Program at Astrakhan State University proved. The trainees believed that it was impossible to tackle the fourth task in Russia. Meanwhile, the real precedents of emergence of turquoise organizations in our country in particular and in the world in general, introduction of holacracy, Agile and Scrum software development prove the opposite: a large number of companies reject the formal hierarchy, form self-managing teams of like-minded people, and develop the company development strategy together. As a result, the organizational structure of a company undergoes changes: large units are split into smaller, more mobile ones, etc. To confirm the fact that managers' conscience is changing in the right direction, let us present the findings of our survey conducted among 30 managers of Astrakhan Region's industrial facilities in 2013. Among the most essential qualities of a modern manager, they named trust and authority among equal-status colleagues (77 \%), ability to establish a management team and delegate responsibility for the most important decisions (76\%), ability to adapt to market changes $(70 \%)$, professionalism in management (57\%), ability to work in various fields efficiently - universalism (56\%), and efficient and productive relations with legal authorities to meet their companies' interests and needs (50\%) [4].

A decade after the new version of management has been developed, cutting-edge Russian companies are already applying its ideas in practice; they adopt management innovations actively and implement such advanced methods of management as adaptive agile, the principles of self-managing holacracy, establishment of requisite organizations, etc. [5,6,7,8]. Among Astrakhan Region's companies, there are already real examples of companies that have adopted agile. Those are the local Sberbank Office and a number of IT companies (Pilot, Adeptik Plus, Best Soft, etc.). As for self-managing companies, now there are only two organizations that have adopted this method: Knopka (Yekaterinburg) and the Tochka online service, as well as the local branch of the Otkritie FC Bank. These companies emphasize everybody's selfcontrol and horizontal control, when colleagues' feedback is of top importance [9].

The world global challenges and new tendencies that Russian companies have to face while the national innovative and digital economy is developing change their development strategies radically. As it is well-known, after Russia had adopted the National Technological Imitative (NTI) in 2014, it reacted to challenges of the Fourth Industrial Revolution by developing its national program of digital transformation by 2035. The NTI matrix includes the following key technologies: artificial intelligence, big data, adaptive technologies, blockchain, sensors and components for robots, neurotechnologies, AR and VR technologies, etc. [10, 11]. In our view, it is digital transformation that can give Russia a new chance to liquidate its technological backwardness, which took place during the post-Soviet era, and help managers select efficient new business models and business development strategies.

As a purposeful impact that encourages people to work together, management may be efficient or inefficient, aimed to achieve short-term or long-term goals depending on numerous factors, including change of priorities in this or that activity, which play the main role at particular historical stages of management development [1, p. 13]. Studies of management evolution, i.e. studies of subsequent stages of development of science related to efficient administration, since early 1990s make it possible 
to determine both its development tendencies and identify the main ideas of efficient management, which may be adopted by modern managers of the $21^{\text {st }}$ century. Based on its generalized theory and managerial practice, which have been dominating in efficient management concepts over the last 30 years, we have identified its main ideas and elements (See Table 1).

Table 1 Evolution of Scientific Concepts Related to Management

\begin{tabular}{|c|c|}
\hline Concepts, Authors & Essence of Concept \\
\hline Learning Organization, P. Senge & $\begin{array}{l}\text { Five features of a learning organization: systems thinking, personal mastery, } \\
\text { mental models, shared vision, and team learning }\end{array}$ \\
\hline $\begin{array}{l}\text { Nonaka and Takeuchi Knowledge } \\
\text { Spiral Model, I. Nonaka and H. } \\
\text { Takeuchi }\end{array}$ & $\begin{array}{l}\text { Creation and dissemination of knowledge based on social interaction of } \\
\text { formalized and non-formalized knowledge between members of staff, not } \\
\text { within an individual }\end{array}$ \\
\hline The High-Velocity Edge, S. J. Spear & $\begin{array}{l}\text { Ability to react to emerging problems or new prospects rapidly and share } \\
\text { knowledge with everyone }\end{array}$ \\
\hline $\begin{array}{l}\text { Creating Shared Value, M. E. Porter } \\
\text { and M. R. Kramer [12] }\end{array}$ & $\begin{array}{l}\text { Principles and methods that give a company a competitive edge and enhance } \\
\text { the social and economic outlook in those regions where it operates }\end{array}$ \\
\hline $\begin{array}{l}\text { The Colleague Letter of Understanding } \\
\text { by the Morning Star \& Company, } \\
\text { which is a world-leading food } \\
\text { processing enterprise. These are letters } \\
\text { written by all the staff members to } \\
\text { describe each employee's roles and } \\
\text { detailed criteria to assess his/her } \\
\text { performance }\end{array}$ & $\begin{array}{l}\text { No chiefs and no official positions, which implies that nobody is promoted; } \\
\text { employee decide themselves who is responsible for what; each staff member } \\
\text { can spend the company's money; each one is responsible for purchasing } \\
\text { whatever is necessary for his or her work; decisions are made only } \\
\text { collectively. }\end{array}$ \\
\hline Holacracy, B. J. Robertson & $\begin{array}{l}\text { The right to make decisions is assigned not to individuals, but to teams of } \\
\text { employees - "circles" and "roles" that do not work on a regular basis. } \\
\text { Authorities and the rights to make a decision are distributed between the } \\
\text { "circles" throughout the company, with management principles declared in } \\
\text { the company Constitution. }\end{array}$ \\
\hline $\begin{array}{l}\text { Agile and Scrum. Principles: } \\
\text { 1. Individuals and interactions over } \\
\text { processes and tools. } \\
\text { 2. Responding to change over } \\
\text { following a plan. } \\
\text { 3. Working software over } \\
\text { comprehensive documentation. } \\
\text { 4. Customer collaboration over } \\
\text { contract negotiation. }\end{array}$ & $\begin{array}{l}\text { Scrum method: a company forms a small ( } 4 \text { to } 10 \text { people) group that includes } \\
\text { all the specialists necessary to accomplish the set task, which control their } \\
\text { work themselves and are responsible for it. There are three key roles within a } \\
\text { team: the Product Owner (PO), the Scrum Master (SM), and the team that } \\
\text { identifies the top-priority tasks itself, breaking them into small modules; } \\
\text { work is done by running short cycles - sprints; the team collaborates with its } \\
\text { customer throughout the entire project and introduces desirable changes. }\end{array}$ \\
\hline $\begin{array}{l}\text { Circles and roles. Circles work to } \\
\text { complete a particular task. A circle is a } \\
\text { team that is formed or dismissed } \\
\text { depending on what a company needs. }\end{array}$ & $\begin{array}{l}\text { In a holacratic circle, a role is a set of duties and commitments necessary to } \\
\text { achieve a particular result or play a definite role. Roles may be created, } \\
\text { reconsidered, or removed; each staff member usually plays several roles in } \\
\text { different circles. }\end{array}$ \\
\hline $\begin{array}{l}\text { HOPE (Haier Open Partnership } \\
\text { Ecosystem) - an open ecosystem for } \\
\text { users, innovators, and partners by } \\
\text { Haier (China), whose staff members } \\
\text { become active entrepreneurs who } \\
\text { report directly to their clients. }\end{array}$ & $\begin{array}{l}\text { An open ecosystem substitutes a formal hierarchy (Haier was split into } 4 \text {, } \\
000 \text { business units - ZZJYTs, each of which employs } 10 \text { to } 15 \text { people). The } \\
\text { company names this approach "rendanheyi", which implies a close } \\
\text { correlation between the value created for a client and the value obtained by } \\
\text { employees. A ZZJYT is formed easily, almost without any centralized } \\
\text { control; all the ZZJYTs apply the same approach to goal setting, reaching } \\
\text { internal agreements, and coordinating their activities. }\end{array}$ \\
\hline
\end{tabular}


Having analyzed the genesis of management concepts over the last three decades, one can see that any concept does not disappear completely once its active phase has been over. Its main ideas continue to exist in present-day concepts based on mutual penetration and enhancement of various elements of management that emerged at this or that time.

One could reflect the idea of a self-managing team suggested by $\mathrm{P}$. Drucker in early 1950s, which was rejected by the society then. Yet, only 4 decades later the idea of self-management (without chiefs) was successfully implemented in its best form by the Morning Star \& Company [13]. Its owner, Chris J. Rufer, who developed and implemented this system, states that everyone in his company is a manager. Everyone is responsible for achieving a strategic goal, for completing the set tasks. To meet the set goals, they are to come to an agreement with their colleagues. Everyone manages the necessary resources. Everyone is a chief who demands productive performance from his or her colleagues. [13, p. 54]. In our view, benchmarking of experience gained by this company is hardly possible for Russian vegetable processing enterprises owing to specifics of Russian business, but it is quite applicable for small businesses in the sphere of services.

At the same time, successful performance of Haier demonstrates a real example of application of many ideas of the Management 2.0 concept for Russian companies as well. The open partnership ecosystem developed by Zhang Ruimin has substituted a formal hierarchy with a natural one. Similar to many other efficient present-day companies, which use flexible self-managing teams, Haier has always placed its clients in the center of its overall activities (in 2010, it had its first entrepreneurial sales and marketing teams, as well as self-managing teams). G. Hamel writes that Haier does everything to turn its staff into its owners. This is the best explanation how this company managed to stimulate innovations and grow very quickly. It is unbelievable that a large global business company has only two levels of managers between the frontline and the CEO [14, p. 55].

Thus, Haier has actually made a very important discovery in the history of management - it took Zhang Ruimin only 10 years to build an organization with a "human-oriented" model of management; he has created an open ecosystem, in which staff members, who have become entrepreneurs, are not just a tool to achieve a goal; they themselves are the goal. Using this model of management that encourages innovations and real action, Haier is able to invent and digitalize new business models easily, which is confirmed by the following results: the annual growth rate of its gross profit is $23 \%$, with its revenue growing by $18 \%$ annually [14, p. 55].

According to G. Hamel, the rendanheyi approach is based on the following seven principles:

1. From Monolithic Businesses to Microenterprises (ME) (Haier was divided into 4, 000 MEs: 200 market-oriented MEs, 50 incubating ones, and 3, 800 node ones; staff of each ME includes 10 to 15 people).
2. From Incremental Goals to Leading Targets. Each ME pursues ambitious goals, so-called "leading targets".

3. From Internal Monopolies to Internal Contracting. Each Haier ME is entitled to decide on its own whether to purchase or not to purchase services offered by other MEs. Top managers hardly ever interfere internal talks. Each node contributes to activities that a market-oriented ME performs, and each employee's salary depends on how well the set goals have been achieved.

4. From Top-Down Coordination to Voluntary Collaboration. Haier MEs are organized into platforms. A platform owner is responsible for building ME teams and helping them find real cooperation opportunities. At that, no one is accountable to the owner, whereas the latter has no subordinates. There is a collective responsibility for customers at Haier.

5. From Rigid Boundaries to Open Innovation. Each new product or service is developed openly. Haier established a network of 400 organizations and experts from all over the world to help it cope with difficult tasks in 1, 000 areas. New project shall not be backed with a large budget until users have supported them.

6. From Innovation Phobia to Entrepreneurship at Scale. Haier has become a real factory of startups; it resembles a giant search system as its MEs scan their battlefield and identify their most promising opportunities.

7. From Employees to Owners. Haier MEs are selfmanaging entities: they have the right to set their goals, identify their opportunities and select the right strategies, employ staff and manage their human resources, determine pay rates, and distribute bonuses $[14$, p. $47-$ $55]$.

Therefore, in response to global challenges and tendencies of the digital economy, one has to take a new look at the task to sustain Russian companies' competitiveness. Their management ought to try to establish a company similar to Haier, which would change at the same pace as its environment, which would involve each employee in innovations on a regular basis, encouraging them to take an initiative, be inventive and creative.

Similar to Haier, Percy Barnevik, Cofounder and CEO of $\mathrm{ABB}$, divided his company into numerous small units 40 to 50 people each in $1990 \mathrm{~s}$. He argued that staff of such small units could manifest their creativity the best way possible, with innovations implemented in real manufacturing at once. As for Russian companies, it is not easy to imagine at once that a Russian company has only two management levels between the frontline and the CEO.

Dr. Ichak Adizes, the renowned guru in the field of management, considers that the Russian model of management has not undergone many changes. He states that people are Russia's best asset. Yet, fear, hierarchy, elitism, and corruption hamper their development in their own country $[15$, p. 5-10]. He identified obstacles that hamper development of an innovative economy in Russia. First of all, those are preservation of an authoritarian style of management, since no manager is able to assess all the risks alone because of chaotic non-stop changes; therefore, coordinated actions of a team are necessary to accomplish 
this task. Hierarchy is being phased out at some Russian enterprises, while systems that reject is completely are being established - holacracy, network organizations, flat structures, agile, etc.

In this case, one should focus on new organizational forms to manage modern companies, which meet the challenges of the Fourth Industrial Revolution better. The Agile approach, which implies a methodology of flexible adaptive management, is no longer a prerogative of technological companies (90\% of IT units have already implemented a flexible model of project management). Gradually and quite actively, it has penetrated such areas as marketing, creation of new products, HRM, and top management (when top managers become another agile team), etc.

Flexible self-managing teams are focused on innovations; they interact with their customers actively and introduce current changes to meet their requirements promptly. Large worldwide companies, such as Spotify, Netflix, Amazon, USAA, Bosch, Saab, ING, SAP, Tesla, apply the agile approach quite successfully.

In Russia, experience gained by Sberbank is well-known. This bank, with the help of McKinsey, has implemented agile not only in its IT units, but also in its HR Department, which applies digital services based on an adaptive technology to automate HR processes, online training, and mass recruiting actively. It also applies chatbots and AI tools. Within less than a year (by February 2018), Sberbank switched to the new cloud platform SAP Success Factors, having transferred the four main HR processes to it: recruiting, personnel adaptation, training, and career development. Having collected all its HR data within a single platform, Sberbank started using analytics and building predictive models of various HR services [16, p. 90-93].

Our participation in various online seminars, webinars, and forums makes it possible to conclude that particular elements and attributes of the agile approach (15-minute standups, customers' participation in accepting prototypes of a product, dashboards, etc.) are already applied by numerous Russian companies in their everyday activities. One could state that this flexible adaptive technology will help both large and small companies develop and implement digital tools.

Owing to digital transformation, approach to business administration is changing, i.e. there is a business model is changed by integrating cutting-edge technologies in all the aspects of business activities, which is a new essential tendency of the present-day reality.

Top management of Russian companies ought to realize that digital transformation requires changes not only in their software, but also in their relations with their suppliers, clients, competitors, and contractors. One should note that there is a rather small number of the $20^{\text {th }}$-century giants (expect for, probably, General Electric, IBM, etc.) among leaders that benefit from applying digital technologies, as it is difficult for them to catch up with startups, which were born in the digital environment. Quite frequently, this is because their traditional business models, which support all the internal systems (stimulation methods, recruiting, staff promotion, distribution of resources, introduction of innovations, etc.) often contradict requirements and needs of digital models [17, p. 60].

At the same time, young startups, which benefit from applying digital technologies, change the old business model actively and create a new one by restructuring their networks of suppliers, partners, and middlemen, i.e. changing numerous elements of the value creation chain.

One should emphasize that adaptability and value of IT infrastructure have decreased so that startups operating in any field can use the most advanced digital developments to adapt quickly to new individualized needs of their clients thanks to customization [18].

Therefore, a large-scale application of tools of digital economy shall definitely exert a real influence upon both the Russian labor market and changes in business models and reduction of planning horizons.

In present-day efficient companies, which perform a digital transformation and which implement new organizational forms such as agile, annual cycles of planning and budgeting have been substituted with shorter ones. Managers who apply the agile flexible technology are aware that an annual cycle restrains innovations, whereas a customer expects frequent changes such as cutting-edge technologies, which may await funding for a long time until a new annual budget cycle has arrived. That is why such companies as Toyota, Tesla, Amazon, etc. have rejected annual planning cycles by substituting them with an immediate reaction to their clients' requests. Elon Musk states that about 20 changes are implemented in Model S every week, which indeed enhances its work $[19$, p. 59].

To resolve the task of creation of a sound digital and innovative economy, it is necessary to consider with specific features of the Russian mentality that hamper its development. One could agree with A. Auzan, who believes that revolutionary reforms in management cannot succeed unless they consider with the "cultural" aspect, which reflects a close link between economy and culture, the national mentality [18]. In his view, the ignored factor is necessity to consider with the national culture and mentality, which is the base underlying all the economic institutions.

Awareness of limits and restraints that exist in the Russian system of management will make it possible to struggle with some particular features and, on the contrary, encourage development of some other features by dwelling on the specific mentality and the national system of values. Let us use the findings of the GLOBE project, which has identified social and cultural factors that favor (or hamper) the development of innovative processes in Russia [20]. The factors that back innovative economy are individualism and a long-term orientation, i.e. looking towards the future. The two factors that hamper its development are a high power distance and a high degree of uncertainly avoidance $[18$, p. 82]. Let us focus on the barriers.

Some research findings prove that Russians are conflictseeking individualists, which is in close relation to their 
low ability to come to a compromise and a lack of trust $[18$, p. 84]. On the other hand, one should consider with Russian people's developing tendencies to unite, work as a team, and get training, as some particular examples of formation of self-learning and self-managing organizations, application of agile and holacracy demonstrate.

A high power distance implies not being prepared to come to an agreement and a strong belief that authorities will tackle all the problems themselves. This is also confirmed with findings of our survey of 30 top managers of various enterprises of Astrakhan Region. The findings have proved that top management of regional enterprises strongly believes in necessity to preserve top managers' monopoly in strategy formation and possess a sufficient amount of leverage to force and persuade all the other participants of the strategic process to accept this vision [4, p. 108-113]. The obtained findings prove that Russia's ordinary citizens are still regarded as "small people", while the authoritarian style prevails in management; people are afraid of disagreeing with their bosses. That is why Russia is still a high power distance country.

Another confirmation of this fact is findings of our diagnostics of the organizational culture of 42 industrial facilities operating in Astrakhan Region (248 employees have completed a questionnaire); this survey has been conducted based on the OKAI technique. A substantial percentage of regional companies $(43 \%)$ have determined their current organizational culture as a hierarchical one, whereas only $36 \%$ (mainly top and middle managers) have indicated the clan culture as a preferable one, whereas common workers and line managers prefer the current hierarchical culture [4, p. 108-113].

The second factor - a high degree of uncertainty avoidance, which is also typical for Russians - reflects the following things: fear of changes, a strong desire to preserve the status quo, an unconditional agreement to work in strict accordance with rules and regulations. People are afraid of losing their jobs even if they are not content with their salaries and work conditions. This factor reflects Russian people's striving for social security and their beliefs that any change may lead only to a negative outcome. Therefore, understanding of restraints that exist in the present-day Russian system of management will help struggle with some particular features and (on the contrary) stimulate the development of other features based on application of the national systems of values and specific mentality. As for the current state of corporate culture of Russian companies, one could state that the organizational culture will improve itself while particular business problems are being resolved by implementing modern management and digital innovations: updating the out-of-date strategy and business model under impact of digital transformation, formation of self-learning and rapidly reacting organizations, creation of self-managing teams, top-down delegation of decision-making, all possible motivation of staff, a lower degree of controlling subordinate employees, a higher degree of trusting them, etc. [21].

\section{CONCLUSION}

Russian managers ought to realize that digital tools are becoming a crucial element to create and develop new business models, penetrate new markets, and form an open ecosystem for consumers, innovators, and partners (as Haier has done). In their turn, new organizational forms of enterprises become the necessary condition for a successful introduction of digital innovations, since they unleash employees' potential in their striving to create a real value for a client, realize themselves as active entrepreneurs who give everyone "a free way towards their dreams" [14, p. 54]. Experience gained by successful world companies presents unique examples of efficient management in the digitalization era.

\section{REFERENCES}

[1] R.I. Akmaeva, Popular Sketches of $21^{\text {st }}$ Century Management, Astrakhan University Publishing House, 2018.

[2] R.I. Akmaeva, Development of Self-Learning Organizations at Industrial Facilities of Present-Day Russia, Astrakhan State Technical University, 2011.

[3] Management 2.0: the New Version for a New Century, in: Harvard Business Review - Russia, October 2009, pp. 91-100.

[4] N. Epifanova, Formation of Rapid-Reaction SelfLearning Organizations at Russian Enterprises, Saint Petersburg Polytechnic University, 2013.

[5] F. Laloux, Reinventing Organizations. A Guide to Creating Organizations Inspired by the Next Stage of Human Consciousness, Mann, Ivanov, and Ferber, 2016.

[6] E. Bernstein, J. Bunch, N. Canner, M. Lee, Beyond the Holacracy Hype, in: Harvard Business Review Russia, October 2016, pp. 31-43.

[7] G. Gref, 2016 Gaydar Forum: Speed, Speed, and Speed, http://json.tv/ict_news_read/german_grefsberbank_rossii-vystuplenie_na_gaydarovskom_forume20160121074319.

[8] D.K. Rigby, J. Sutherland, H. Takeuchi, Embracing Agile: How to Master the Process That's Transforming Management, in: Harvard Business Review - Russia, August 2016, pp. 39-42.

[9] R.I. Akmaeva, N. Epifanova, V. Zhukov, Opportunities of Agile for Management, Bulletin of Astrakhan State Technical University, 2017(1), pp. 715 . 
[17] M. Wessel, A. Levie, R. Siegel, The Problem with Legacy Ecosystems, in: Harvard Business Review Russia, March 2017, https://hbrrussia.ru/management/strategiya/a19181.

[18] A. Auzan, Will Russia Be Able to Escape from the Trap, in: Harvard Business Review - Russia, June-July 2016, pp. 81-85.

[19] D.K. Rigby, J. Sutherland, A. Noble, Agile at Scale, in: Harvard Business Review - Russia, August 2018, p. 59.

[20] M. Grachev, Management in "the International System of Coordinates", in: Economic Strategies, 1999(2), pp. 19-32.

[21] R.I. Akmaeva, N. Epifanova, K. Makarov, Assessing the Influence of Russian Mentality upon Formation of Companies' Innovative and Strategic Behavior, Bulletin of Astrakhan State Technical University, 2018(3), pp. 7-17.

[16] Yu. Fukolova, Digitalized HR. How Sberbank Implements Digital Methods of HRM, in: Harvard Business Review - Russia, August 2018, pp. 90-93. 